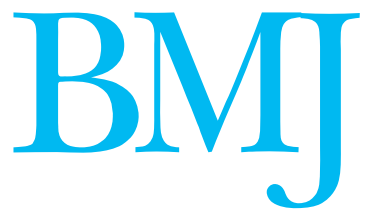

\title{
Chronic disease care
}

\section{Insights from managed care in the United States will help the NHS}

$\mathrm{T}$ wo papers in this issue of $B M J$ examine developments in the management of chronic illness in the United States and explore their potential relevance to recent NHS initiatives and policies. ${ }^{12}$ A new King's Fund study of the care of chronically ill people in five leading US managed care organisations, summarised in the paper by Dixon et al ( $\mathrm{p} 220$ ), provides several observations and insights of relevance to new NHS initiatives targeting care of chronic illness. ${ }^{1}$ The authors conclude that the success of these organisations relates to five factors, which serve as the basis for their recommendations for NHS action. With some minor exceptions, I believe that their observations and recommendations are on target and worthy of serious consideration by policy makers in the United Kingdom.

\section{Competition}

The investigators were struck by the intensity of market forces in US health care and although these contributed to variability, excesses, and doctors' discontent, they came away convinced that market forces pushed organisations to improve their quality. ${ }^{4}$ This is debatable. The perceived lack of a compelling business case for quality reinforces the market pressures to control costs and

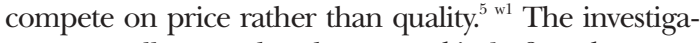
tors are well aware that the wrong kind of market pressures could be disruptive and even a threat to quality of care and are appropriately cautious in recommending steps to foster competition within the NHS.

\section{Ownership and exclusive contracting}

Relationships between the managed care organisations and their clinicians were found to vary within and between organisations. Two managed care organisations contract exclusively with one or two medical groups. In a third, contracted doctors care for subscribers of multiple managed care organisations. The remaining two use a mixture of exclusive and non-exclusive contracts. Although few research data show quality advantages for one managed care organisation's model over others, ${ }^{6}$ the report concludes that exclusivity of relationships fosters greater commitment by clinicians to organisational success, involvement in decision making, and closer relationships with managers of managed care organisations. In return managed care organisations are more willing to invest in frontline infrastructure such as clinical information systems. My experience in one of the two mixed model managed care organisations strongly confirms the

\section{Integration between providers}

The report underscores the importance of linking and coordinating primary and specialist care for patients with chronic illness. Some evidence shows that closer integration of primary and specialist care improves health care for individual patients ${ }^{7 \mathrm{w} 2 \mathrm{w} 3}$ and for populations of patients. ${ }^{8}$ In some of the managed care organisations studied this is made easy by their membership in the same medical group or presence in the same physical facility. In others, functional linkages are created through shared information, shared guidelines, and staff to coordinate care (for example, case managers). In all organisations health care is facilitated by the alignment of goals-for example, to minimise hospitalisation-between the primary care and specialty sectors. Alignment of goals and promotion of coordinated care by teams consisting of generalists and specialists-as in the personal medical services pilots ${ }^{9}$ should be a high priority.

\section{Financial incentives}

Financial incentives to reward high quality chronic illness care are important elements of the strategies of managed care organisations studied. The incentives tend to be modest, in the range of $5-10 \%$ of salary. This amount is felt to be large enough to change clinical behaviour, but not so large as to encourage inappropriate or fraudulent efforts to obtain a bonus. In addition to giving incentives to individual clinicians some managed care organisations offer incentives to contracting medical groups to reward high quality care. Evidence from a recent study of randomly sampled large US medical groups found that organisational incentives encouraged the implementation of system improvements supportive of better chronic care. ${ }^{\mathrm{w} 4}$ The efforts in the NHS to build performance based incentives into contracts is clearly a step in the right direction, if based on credible indicators of better care and trustworthy measures.

\section{Clinical process: chronic disease management}

All five managed care organisations use explicit models and strategies for improving their systems of care. All have made comprehensive changes to their systems to encourage and support better care, including more support for self management by patients, more structured visits and patient follow up, clinical case management of more complex patients, and enhancements to decision

Additional references w1-w5 are on bmj.com 
support and clinical information systems. These changes are consistent with the chronic care model, a synthesis of system components and strategies associated with effective care across conditions. ${ }^{\mathrm{w} 5}$ Three managed care organisations explicitly use the chronic care model as the guide to changing systems.

In their paper on page 223, Lewis and Dixon relate policy developments in the NHS to the elements of the chronic care model and conclude that recent NHS policy and planning initiatives are addressing many of the essential elements of high quality chronic illness care. $^{2}$ But these efforts would benefit from a "clear generic model of disease management." To be more relevant to the British context, the chronic care model or any other model must link the macro policy environment to frontline care and the needs of patients.

These two papers, on balance, show that the recently launched NHS push to improve care of chronic diseases is on the right track and is likely to have much to teach the United States and other countries. The growing epidemic of chronic diseases in developing countries will be one of the topics covered in the BMJ's fourth theme issue on chronic disease care in January 2005.

\section{Edward H Wagner director}

MacColl Institute for Healthcare Innovation, Center for Health Studies, Group Health Cooperative, 1730 Minor Avenue, Suite 1290, Seattle, WA 98101, USA (wagner.e@ghc.org)

Competing interests: EW is the leader of the team that developed the chronic care model funded by the Robert Wood Johnson Foundation.

1 Dixon J, Lewis R, Rosen R, Finlayson B, Gray D. Can the NHS learn form US managed care organisations? BMJ 2004;328:220-2.

2 Lewis R, Dixon J. Rethinking management of chronic diseases. BMJ 2004:328:223-6.

3 Fisher ES, Wennberg DE, Stukel TA, Gottlieb DJ, Lucas FL, Pinder EL. The implications of regional variations in Medicare spending. Part 2: health outcomes and satisfaction with care. Ann Intern Med 2003;138:288-98.

4 Mechanic D. Physician discontent: challenges and opportunities. JAMA 2003;290:941-6.

5 Casalino LP. Markets and medicine: barriers to creating a "business case for quality". Perspect Biol Med 2003;46:38-51.

6 Miller RH, Luft HS. HMO plan performance update: an analysis of the literature, 1997-2001. Health Aff (Millwood) 2002;21:63-86.

Rothman AA, Wagner EH. Chronic illness management: what is the role of primary care. Ann Intern Med 2003;138:256-61.

8 McCulloch DK, Price MJ, Hindmarsh M, Wagner EH. A population-based approach to diabetes management in a primary care setting: early results and lessons learned. Effective Clin Pract 1998;1:12-22.

9 Richardson T, Roscoe A. PMS plus-developing a new organization and extending services. In Lewis R, Gillam S, Jenkins C, eds. Personal medical services pilots-modernising primary care? London: King's Fund, 2001.

\title{
Reconfiguration of surgical, emergency, and trauma services in the United Kingdom
}

\author{
Centralisation of services is politically impossible
}

$\mathrm{T}$ o find the royal colleges proposing that acute inpatient care in the United Kingdom should be provided in fewer, larger, better equipped, and better staffed hospitals is not unusual. What would be unusual would be to find a government two years out from a general election rushing to implement such advice. The Senate of Surgery of Great Britain (comprising the four surgical royal colleges, the dental faculties, and 10 surgical specialty associations) has published a policy paper that seeks to speak with a single voice for the surgical community (www.rcpsg.ac.uk/recreport. $\mathrm{htm}) .{ }^{1}$ This policy paper signals a wish for a debate on this controversial topic and a wish to participate.

These surgeons want a lot-and not for the first time, and not just the surgeons. The senate suggested something similar in 1997, but it did not happen. ${ }^{2}$ The Royal College of Physicians wants to phase out acute emergency admissions from isolated smaller units and transfer the work to properly equipped and staffed larger units. ${ }^{3}$ The arguments are cogent and extensively made-in surgery, medicine, paediatrics, and maternity care. The impending need to comply with the European Working Time Directive-a regulation of the European Union limiting a doctor's working week to an average of 56 hours, which comes into force in August 2004-is adding velocity to a general demand among professional advisory bodies to concentrate the medical workforce in fewer, larger, acute centres.

At this stage in the United Kingdom electoral cycle (with an upcoming election in which the NHS is guaranteed a central place among the issues), does anyone expect to see the rapid implementation of policies that

\section{Conditions for the new pattern set by the senate}

- Must be acceptable to the public

- Make coordinated care from first presentation to rehabilitation and return to home possible

- All surgeons are to have adequate clinical experience and training opportunities

- Services are to be cost effective; the importance of outcome data is to be recognised

- Internationally accepted standards of surgery are to determine the reception of all surgical patients in all centres irrespective of size

- Complex surgical inpatients are to be treated in larger hospitals

will be perceived to "downgrade" the importance of perhaps 50 or more acute hospitals? When asked to take a tough decision, Richard Nixon was alleged to ask, "Does it play in Peoria, Illinois?" Badly.

Perhaps the senate's members will be in a difficult position for some time to come until one of two ways forward is cleared. Firstly, they could connect their ambition for greater centralisation of complex acute cases to the realpolitik of constituency affairs and provide the politicians with a means of winning votes by implementing them. The Kidderminster debacle will be fresh in all politicians' minds. (Kidderminster is a town in England that voted out both the local council and member of parliament and replaced them with single issue candidates dedicated to saving the local hospital.) Any local proposals for reconfiguration of hospital services will have to negotiate a substantial nexus of legal and political processes. The history of these consultations 